www.jmscr.igmpublication.org

Index Copernicus Value: 79.54

ISSN (e)-2347-176x ISSN (p) 2455-0450

crossrefDOI: https://dx.doi.org/10.18535/jmscr/v7i3.103

\title{
Psychometric Hepatic Encephalopathy Score for the Detection of Minimal Hepatic Encephalopathy in South Indian patients with Liver Cirrhosis
}

Authors

\section{Kumaravel Gopal ${ }^{1}$, Pradeep Kumar Mamallan ${ }^{2 *}$, Dhananjayan Kannan ${ }^{3}$, Suresh Paul Raj Mohan Raj ${ }^{4}$}

${ }^{1,2}$ Assistant Professor, Department of General Medicine, Government Kilpauk Medical College and Hospital, Chennai- 600010

${ }^{3}$ Senior Assistant Professor, Department of General Medicine, Government Kilpauk Medical College and

Hospital, Chennai- 600010

${ }^{4}$ Junior Resident, Department of General Medicine, Government Kilpauk Medical College and Hospital,

Chennai- 600010

*Corresponding Author

Pradeep Kumar Mamallan

Assistant Professor, Department of General Medicine, Government Kilpauk Medical College and Hospital,

Chennai - 600010, India

Email: pradeepgenmed@gmail.com, Mobile: 9444833555

\begin{abstract}
Background: $M H E$ is the mild form of spectrum of $H E$, defined as a mild neurocognitive and psychomotor disorder present in cirrhotic patients. MHE is not recognizable on usual clinical examination, requiring the use of PHES.The objective of this study was to standardize PHES ${ }^{[4]}$ in healthy south Indian population and evaluate the prevalence of MHE among south Indian patients with cirrhosis.

Materials and Methods: This is a case control study done at Kilpauk Medical College. 40 cases diagnosed as cirrhosis admitted there and 40 controls were subjected to PHES testing.

Results: 19 patients (47.5\%) with cirrhosis were diagnosed with MHE in present study with PHES score.

Conclusion: PHES study is statistically significant in detecting MHE in cirrhotic patients, and correlates with severity.

Keywords: Encephalopathy, Cirrhosis, Ammonia,Ascites, Bilirubin.
\end{abstract}

\section{Background}

MHE ${ }^{[3]}$ is seen in $30-85 \%$ of cirrhotic patients.

The main pathogenic mechanism for $\mathrm{HE}$ is increase in ammonia and inflammation leading to swelling of astrocytes in brain and cerebral edema. PHES is the gold standard in diagnosis of MHE in patients with cirrhosis. The scoring consists of Number Connection tests A and B,
Digit Symbol test, Line Drawing test and Circle Dotting test. Impairment of $>2 \mathrm{SD}$ in 2 or more tests is necessary for diagnosis of MHE.

\section{Materials and Methods}

40 patients with cirrhosis are selected from Kilpauk Medical College, along with 40 controls. 
Inclusion Criteria

- Age $>18$ years

- Confirmed to have cirrhosis

\section{Exclusion Criteria}

\section{Cases \& Controls}

- Psychiatric or neurological disorders,

- Psychotropic drugs usage

- Alcohol > 50g/day within last 3 months.

- Inability to read and write.

\section{Cases}

- Overt HE

- Consumption of lactulose/ antibiotics.

Study Design- Case Control Study

Study Duration- July 2018 to December 2018

Statistical Methods Applied

Data was analyzed using the SPSS software. Statistical significance was indicated by the chisquare test. Variables were considered to be significant if $\mathrm{p}<0.05$

\section{Results}

- In our study, mean age of controls is 45.3, mean age of controls is 45.28. Approximately equal in number in each age group, between cases and controls, p value is 0.987 , so no age-wise statistical difference present.

- Controls had 32 males \& 8 females to cases with 31 males and 9 females, $p$ value is 0.785 , so statistical significance present.

- In NCT-A, 21 cases were PHES positive, 19 were PHES negative. The mean value in cases was 77.28, and in controls 65.63.

- In NCT-B, 26 cases were PHES positive and 14 cases were PHES negative. The mean value in cases was 115.05, and in controls was 91.80.

- In DST, all 40 cases were PHES positive. The mean value in cases was 17.83, and in controls 24.65.

- In LDT, 27 cases were PHES positive, 13 cases were PHES negative. The mean value in cases was 76.83 and in controls 64.03.
- In CDT, 24 cases were PHES positive, 16 were PHES negative. The mean value in cases was 79.83 and in controls 66.47.

- From this study, PHES was positive in 19 cases and 2 controls. p value $<0.001$, so MHE is present in 19 cases(47.5\%) out of 40 .

- Out of these 19 cases, ascites was detected in 11 cases, so chances of MHE is more in decompensated liver disease.

- Out of the 40 cases, bilirubin > 5.405 and ammonia > 93microgram/dl in 19 cases, bilirubin< 2.681 and ammonia $<78$ microgram/dl in the remaining 21 cases.

- Out of these 19 cases, EEG changes were observed only in 3 cases, so EEG does not help to detect patients with MHE, it can be a follow up tool.

\section{Age Distribution}

\begin{tabular}{|l|c|c|}
\hline AGE & CONTROL & STUDY GROUP \\
\hline $20-30$ & 0 & 2 \\
\hline $31-40$ & 12 & 8 \\
\hline $41-50$ & 16 & 19 \\
\hline $51-60$ & 12 & 11 \\
\hline TOTAL & 40 & 40 \\
\hline
\end{tabular}

Sex Distribution

\begin{tabular}{|l|c|c|}
\hline GROUP & MALE & FEMALE \\
\hline CONTROL & 32 & 8 \\
\hline CASES & 31 & 9 \\
\hline TOTAL & 63 & 17 \\
\hline
\end{tabular}

NCT-A

\begin{tabular}{|l|c|c|c|c|}
\hline GROUP & NO. & MEAN & SD & $\begin{array}{c}\text { STD } \\
\text { ERROR } \\
\text { MEAN }\end{array}$ \\
\hline CONTROLS & 40 & 65.63 & 9.599 & 1.518 \\
\hline CASES & 40 & 77.28 & 15.436 & 2.441 \\
\hline
\end{tabular}

P Value O.OOO $(<0.001$ - highly significant $)$

\begin{tabular}{|l|c|c|}
\hline CASES & NUMBER & $\begin{array}{c}\text { \% WITHIN } \\
\text { THE GROUP }\end{array}$ \\
\hline POSITIVE & 21 & 52.5 \\
\hline NEGATIVE & 19 & 47.5 \\
\hline
\end{tabular}

NCT-B

\begin{tabular}{|l|c|c|c|c|}
\hline GROUP & NO. & MEAN & SD & $\begin{array}{c}\text { STD } \\
\text { ERROR } \\
\text { MEAN }\end{array}$ \\
\hline CONTROLS & 40 & 91.80 & 10.528 & 1.665 \\
\hline CASES & 40 & 115.05 & 35.682 & 5.642 \\
\hline
\end{tabular}




\begin{tabular}{|l|c|c|}
\hline CASES & NO. & $\%$ WITHIN THE GROUP \\
\hline POSITIVE & 26 & 65 \\
\hline NEGATIVE & 14 & 35 \\
\hline
\end{tabular}

DST

\begin{tabular}{|l|c|c|c|c|}
\hline GROUP & NO. & MEAN & SD & $\begin{array}{c}\text { STD } \\
\text { ERROR } \\
\text { MEAN }\end{array}$ \\
\hline CONTROLS & 40 & 24.65 & 4.389 & 0.694 \\
\hline CASES & 40 & 17.83 & 5.879 & 0.929 \\
\hline
\end{tabular}

\begin{tabular}{|l|c|c|}
\hline CASES & NO. & \% WITHIN THE GROUP \\
\hline POSITIVE & 40 & 100 \\
\hline NEGATIVE & 0 & 0 \\
\hline
\end{tabular}

LDT

\begin{tabular}{|l|c|c|c|c|}
\hline GROUP & NO. & MEAN & SD & $\begin{array}{c}\text { STD } \\
\text { ERROR } \\
\text { MEAN }\end{array}$ \\
\hline CONTROLS & 40 & 64.03 & 10.154 & 1.605 \\
\hline CASES & 40 & 76.83 & 15.387 & 2.433 \\
\hline
\end{tabular}

P VALUE $0.0(<0.001$ - highly significant $)$

\begin{tabular}{|l|c|c|}
\hline CASES & NO. & \% WITHIN THE GROUP \\
\hline POSITIVE & 27 & 67.5 \\
\hline NEGATIVE & 13 & 32.5 \\
\hline
\end{tabular}

CDT

\begin{tabular}{|l|c|c|c|c|}
\hline GROUP & NO. & MEAN & SD & $\begin{array}{c}\text { STD } \\
\text { ERROR } \\
\text { MEAN }\end{array}$ \\
\hline CONTROLS & 40 & 66.47 & 8.910 & 1.409 \\
\hline CASES & 40 & 79.83 & 16.175 & 2.558 \\
\hline
\end{tabular}

P VALUE $0.0(<0.001$ - highly significant $)$

\begin{tabular}{|l|c|c|}
\hline CASES & NO. & $\%$ WITHIN THE GROUP \\
\hline POSITIVE & 24 & 60 \\
\hline NEGATIVE & 16 & 40 \\
\hline
\end{tabular}

\section{Discussion}

Correlation with Severity

In the previous studies, Child Pugh B and C had high PHES positivity. In the present study, cases with ascites had higher proportion of PHES positivity. so, decompensated liver disease patients are more prone for MHE.

Correlation with Serum Ammonia

Patients with severe liver disease with increased ammonia levels had high PHES positivity ${ }^{[5]}$.

Correlation with EEG

EEG is not effective in detecting MHE. It can be used for follow up of $\mathrm{HE}^{[6] \text {. }}$

Some of the precipitants for HE are:

- Sepsis
- GI bleed

- Constipation

- Excess protein diet ${ }^{[1]}$

- Uremia

- Hypokalemia

- Alkalosis

- Dehydration

- TIPSS $^{[2]}$

\section{Conclusion}

- PHES score is statistically significant in detecting minimal hepatic encephalopathy in cirrhotic patients.

- Incidence of MHE is more severe with severe liver dysfunction.

\section{Bibliography}

1. Shawcross, D.L.Wright, G.Olde damink, s.w. \& jalan.R, systemic inflammatory response exacerbates the neuropsychological effects of induced hyperammonemia in cirrhosis .J.Hepatol.40,247-254 [2004]

2. Karin Weissenborn Diagnosis of subclinical hepatic encephalopathy Med sci Monit, 1999; 5 [3]:568-575.

3. Radha k.dhiman.yogesh $\mathrm{K}$ Chawla. Minimal hepatic encephalopathy. Indian J Gastroenterol 2009:18:5 - 16.

4. seo ys, yim sy, yung JY, Kim CH. Psychometric hepatic encephalopathy score for the detection of minimal hepatic encephalopathy in Korean patients with liver cirrhosis, J, Gastroenterol hepatol 2012 nov; 27[11]:1695-704.

5. Lockwood AH, Yap EW, Wong WH. Cerebral ammonia metabolism in patients with severe liver disease and minimal HE. J Cereb Blood flow metab 1991; 11:337341.

6. Amodio p, Del Piccolo F, Petteno E, et al, prevalence and prognostic value of EEG alterations in cirrhotic patients. J. Hepatol 2001; 35:37-45. 


\footnotetext{
Abbreviations

MHE - minimal hepatic encephalopathy

HE - hepatic encephalopathy

NCT - number connection test

DST - digit symbol test

CDT - circle dotting test

LDT - line drawing test

TIPSS - Trans jugular intrahepatic Porto systemic

shunt

PHES- psychometric hepatic encephalopathy score
} 